\title{
Identification and evaluation of ecosystem services for a regional park: a case study in Italy
}

\author{
T. Pedone ${ }^{1}$, L. Coscieme ${ }^{1}$, S. Ferrini ${ }^{2}$ \& F. M. Pulselli ${ }^{1}$ \\ ${ }^{1}$ Ecodynamics Group, Department of Earth, Environmental and \\ Physical Sciences, University of Siena, Italy \\ ${ }^{2}$ Department of Economics, University of Siena, Italy
}

\begin{abstract}
This paper analyses the ecosystem services provided by a regional park in the South of Italy. The park, constituted by 12 municipalities, aims at facilitating a smart management of cultural-historic and environmental heritage as well as the optimization in the use of local resources and peculiarities. The ecosystem services actually provided by the park (e.g. $\mathrm{CO}_{2}$ sequestration) or potentially usable (e.g. the production of olive-oil) have been identified. The aim is to highlight the essential importance of the natural capital stock and the services it provides for the local economy and for those who can take benefit from them. Neglecting the ecosystem services' value in decision making processes entails the loss of several assets - in some cases un-replaceable, such as local biodiversity - which may imply serious consequences for the overall ecosystem and the sustainability of the local economic system.
\end{abstract}

\section{Introduction}

Urban settlements should be considered and studied in connection with the environmental context that contains them. The urban system, to be completely functional to the inhabitants, has often been viewed as dependent on the exchange of energy, matter, information, money, people, etc. with the external environment. The city can be assimilated to a thermodynamically non-isolated system in which inflows and outflows of energy and matter play a crucial role for its survival. Ilya Prigogine, Nobel Prize in chemistry in 1977, said that one of the clearest example of "dissipative structure" (defined as thermodynamic systems, open to energy and 
matter that self-organize towards higher complexity and organization of matter, creating order out of chaos [1]) is the city in connection with the countryside [2].

The relationship between any urban system and its environmental context must be always taken into consideration, and a number of possible territorial planning configurations can be adopted to emphasize this virtuous link. The urbanenvironment connection is particularly emphasized when a body of rules, restrictions and opportunities is referred to a circumscribed system, like a protected area. Protected areas, like natural reserves or regional parks, have an important role in this sense. According to the IUCN (http://www.iucn.org/) "a protected area is a clearly defined geographical space, recognised, dedicated and managed, through legal or other effective means, to achieve the long term conservation of nature with associated ecosystem services and cultural values".

In particular, protected areas are important providers of ecosystem services (ESs) to the society, the economy and the urban system. The ESs can be defined as all the benefits that people obtain, directly or indirectly, from nature [3]. They include supply of food, material and freshwater, but also climate regulation, nutrient and water cycling, protection from impacts of natural disasters, as well as the well-being obtained from the view of a beautiful landscape. The importance to preserve and protect ESs, biodiversity and natural and cultural assets is internationally recognized. The EU Habitat Directive (92/43/CEE) [4] represents the cornerstone of Europe's nature conservation policy. The Directive aims at preserving both natural and semi-natural areas, where the latter refers to those areas in which humans and nature have always lived in symbiosis, with a virtuous exchange of services from nature to men (like ESs provisioning) and from men to nature (taking care about the environment).

This paper aims at inventorying and evaluating the ESs provided by the regional park "Costa Otranto-S.M. di Leuca e Bosco di Tricase" in the Apulia Region, South Italy. It can be considered an example of a symbiotic system of humans and nature, in which the protection of natural habitats and biodiversity is coupled with the conservation of cultural values and traditional activities.

\section{Methods}

Several classifications of ESs are available [3, 5-8], but the most comprehensive work has been done by the Millennium Ecosystem Assessment [3], which classifies ESs in four categories:

1. provisioning services: include all the biomass produced by ecosystems and directly used by human such as food, water, timber, and fiber;

2. regulating services: sustain the functioning of the ecosystems, regulating important elements like climate, floods, diseases, wastes, and water quality;

3. supporting services: are necessary to support all other ESs, such as soil formation, photosynthesis, and nutrient or water cycling;

4. cultural services: provide recreational, aesthetic, and spiritual benefits, and affect all intangible values derived from the contact with nature.

This classification, despite is clarity, does not provide guidance to an efficient economic evaluation of ESs which needs to pinpoint the "final good" enjoyed by 
the people that directly affects their well-being [9]. The attention to "final good" was originally proposed by Fisher et al. [6] and implies that all the intermediate processes and services (like supporting services) that constitute the "back-office" provider of the overall ESs cannot be considered in the economic analysis.

An attempt to improve the economic evaluation of ESs has been done by the UK government which, in 2011, published the first UK National Ecosystem Assessment [8]. This classification disentangles ecosystem process/intermediate services and final services to improve the economic evaluation of ESs. In this work we follow this approach with the aim of identifying and quantifying the ESs of the regional park under study.

\subsection{Study area}

The natural regional park "Costa Otranto-S.M. di Leuca e Bosco di Tricase" is located in Apulia, in the province of Lecce (Italy). Established in 2006, it partially includes 12 municipalities, as shown in Figure 1. The park is a Site of Community Importance and part of the Nature 2000 network created by the Habitat Directive (92/43/CEE) [4].

The park covers about 3160 hectares and develops along $57 \mathrm{~km}$ on the Salento's south-east coastline on the Adriatic Sea. It includes several natural and cultural amenities. Several different habitats can be found: pine forest, holm and oak forest, olive trees, scrub, cliff and caves that sustain a landscape rich biodiversity with some endemic species. It is also a fundamental stopover site for many migratory birds.

The natural landscape of this area has been modified by human activities since the Paleolithic age. There are prehistoric paintings in some caves, megalithic monuments, rural architectures (like drystone walls and pajare - a rural traditional stone-building of Salento, coastline towers, castles, churches and many other buildings: all evidences of a long human history in this region). The richness of the heritage has promoted different tourist activities in the country and at the seaside. Biodiversity and ESs therefore contribute to the well-being of people and animals that live, or just visit, the park.

\subsection{Data collection}

The assessment of ESs requires scientific and biological knowledge as well as social and economic skills. Therefore, many different sources of information have been used for this analysis. The methodology and data collection depend on the ESs analysed.

As a general rule, a bottom-up approach has been used and data are collected starting from the local level. The most important source of data was provided by the park administration. The "Atlante del Parco" [10] contains all general environmental and socio-economic characteristics of the area.

At the local level, the dataset was integrated with information from local experts and ad-hoc questionnaires designed for the main stakeholders of the area (e.g. farmers). 
Occasionally, site-specific data have been integrated with information from Regional and National Statistics. For example, for identifying ESs from biomass, olive-oil production and water flow, we relied on regional data sources. In other cases (e.g. the value of fresh forage for grazing) an intense literature review has been performed. Moreover, the IPCC methodology [11] for valuing carbon sequestration service has been used to account for the trees and scrubs carbon storage.

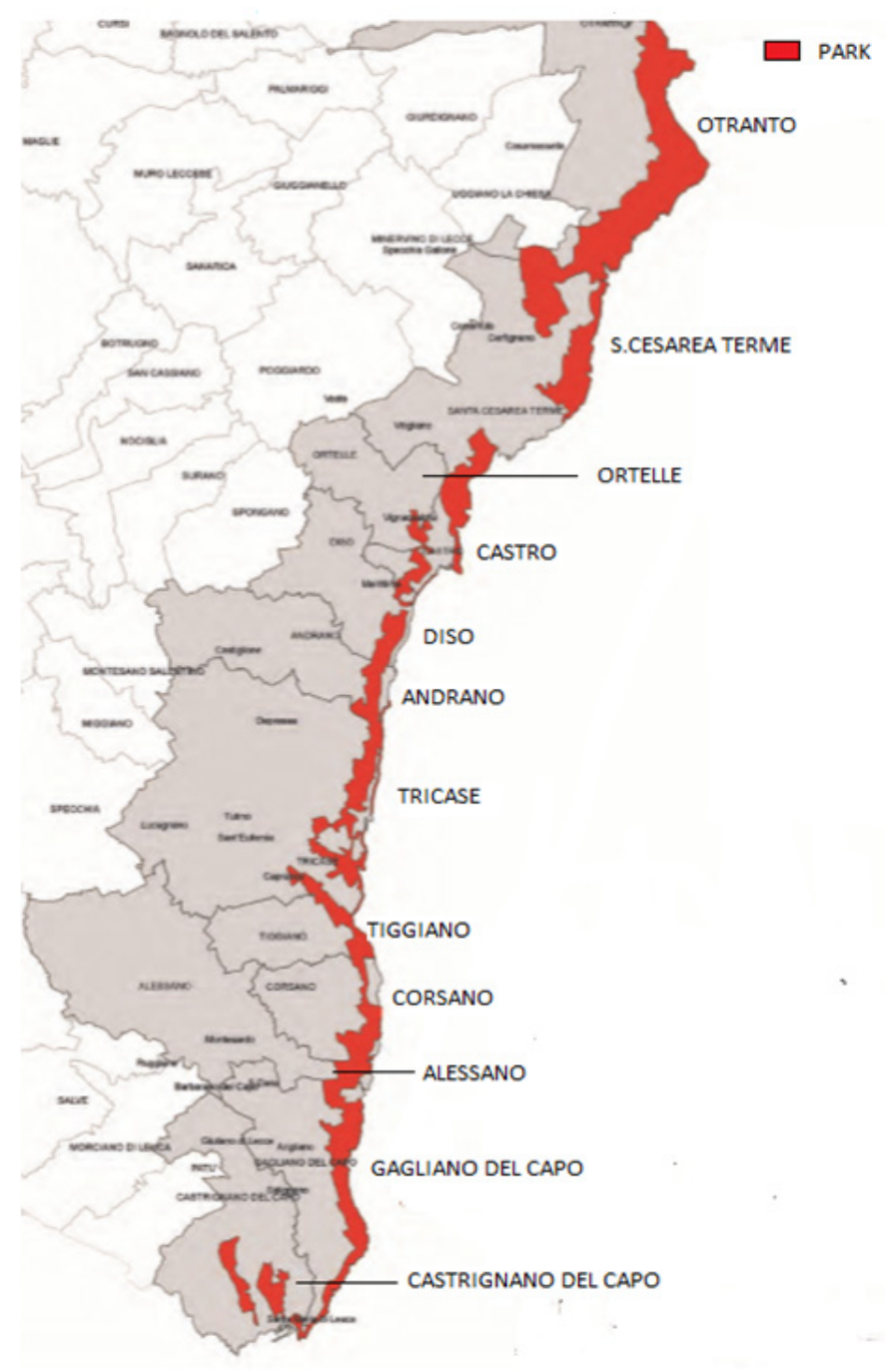

Figure 1: The regional park "Costa Otranto-S.M. di Leuca e Bosco di Tricase". 


\section{Results}

The ESs inventory is summarized in Table 1. The first column shows the general ecosystem processes and functions that allow the provisioning of the final output; the second column reports the final ESs which influence people's well-being. In the third column, we suggest the best economic methodology for ES assessment. For five of these ESs, we propose an economic assessment. They have been selected due to the relevance in the study area and data availability.

Table 1: $\quad$ Ecosystem services inventory of the park and the main methods that can be used for evaluation.

\begin{tabular}{|c|c|c|}
\hline $\begin{array}{l}\text { Ecosystem process - } \\
\text { intermediate services }\end{array}$ & Final ES $\rightarrow \operatorname{good}$ & $\begin{array}{c}\text { Economic assessment } \\
\text { method }\end{array}$ \\
\hline \multirow{3}{*}{ Gas regulation } & Clean air & $\begin{array}{l}\text { Avoided cost, hedonic price, } \\
\text { stated preferences, benefit } \\
\text { transfer }\end{array}$ \\
\hline & Carbon sequestration & $\begin{array}{l}\text { Marginal abatement cost, } \\
\text { benefit transfer }\end{array}$ \\
\hline & Shadow and shelter & $\begin{array}{l}\text { Stated preferences, benefit } \\
\text { transfer }\end{array}$ \\
\hline \multirow{3}{*}{ Primary production } & Biomass & $\begin{array}{l}\text { Avoided cost, adjusted market } \\
\text { price, benefit transfer }\end{array}$ \\
\hline & Food & $\begin{array}{l}\text { Adjusted market price, benefit } \\
\text { transfer }\end{array}$ \\
\hline & Forage & Avoided cost, benefit transfer \\
\hline Nutrient cycle & Soil fertility & $\begin{array}{l}\text { Avoided cost, replacement } \\
\text { cost, benefit transfer }\end{array}$ \\
\hline Water cycle & Drinking water & $\begin{array}{l}\text { Avoided cost, replacement } \\
\text { cost, stated preferences, } \\
\text { benefit transfer }\end{array}$ \\
\hline Ecological interactions & Biodiversity & $\begin{array}{l}\text { Avoided cost, stated } \\
\text { preferences, benefit transfer }\end{array}$ \\
\hline \multirow{3}{*}{ Evolutionary processes } & $\begin{array}{c}\text { Tourist }- \\
\text { recreational activities }\end{array}$ & \multirow{3}{*}{$\begin{array}{l}\text { Stated and revealed } \\
\text { preferences, benefit transfer }\end{array}$} \\
\hline & $\begin{array}{c}\text { Historic - } \\
\text { cultural and spiritual values }\end{array}$ & \\
\hline & $\begin{array}{l}\text { Intrinsic value: } \\
\text { cultural identity }\end{array}$ & \\
\hline
\end{tabular}

\subsection{Carbon sequestration}

The area considered for this analysis covers 1370 hectares and includes different plants: olive trees, orchard, vineyard, small holm and oak forest, pine forest and Mediterranean scrub. According to the methodology given by the IPCC [11] for the computation of carbon, this area captures annually 1.491 tons of $\mathrm{CO}_{2}$. By coupling the quantity of carbon with its marginal abatement cost [12], we can determine the economic value of carbon sequestration. Several methods have been proposed to assess the economic value of carbon $[13,14]$. The marginal abatement cost approach considers the cost of one ton of $\mathrm{CO}_{2}$ based on actual available technologies and hypothetical scenarios of GHG emissions in a defined period. 
This methodology, based on a target-consistent approach of carbon emissions reduction, has been preferred also by the UK Government instead of the Social Cost of Carbon, which implies more uncertainty [14]. The resulting economic value of carbon sequestration is calculated between 52,000€ and 155,000€ in 2014, with an average value of 104,000€.

Future impacts of global warming would increase the value of this service which can be valued as $379,000 €$ in $2050(\min 190,000 €-\max 569,000 €)$.

\subsection{Extra-virgin olive oil}

The olive oil is a high quality product in Apulia, and is obtainable in a large amount from the 801 hectares of olive trees inside the park. The oil production could be achieved with an efficient common management of these plants, but the production has not been set yet. However, in line with the future aims of the park administration [10], we assume that the production would effectively be implemented.

Considering three levels of olive productivity per hectare (low, medium and high), we obtain different quantities of olives, that generate 128, 185 and 371 tons of extra-virgin oil, respectively. The production costs were subtracted from revenues. Revenues are obtained considering two selling prices: $2.5 € / 1$ as a commercial discount price; and $7.8 € / 1$ as a medium retailed local producer's price. The economic value of extra-virgin olive oil is presented in Table 2.

Table 2: Olive oil potential revenues.

\begin{tabular}{|l|c|c|}
\hline $\begin{array}{l}\text { Extra-virgin olive oil } \\
\text { production }\end{array}$ & Net revenues & Net Revenues \\
$2.5 € / 1$ & $€ .8 € / 1$ \\
\hline Low & $€ 187,000$ & $€ 870,600$ \\
\hline Medium & $€ 271,000$ & $€ 1,262,400$ \\
\hline High & $€ 542,000$ & $€ 2,524,800$ \\
\hline
\end{tabular}

\subsection{Biomass production}

The residual biomass from agriculture is not yet exploited in this area. In our scenario, the biomass production is correlated to the olive oil production and can maximize profits from the management of olive trees. Both the production of olive oil and biomass are solutions to enhance economic benefits from a natural service provided by the park's ecosystem.

The hypothesis is to sell piles of olive wood, each one of $30 \mathrm{~kg}$, to local businesses like restaurants, pizzerias and bakeries that normally use wood for cooking. Considering the cost of pruning, and a selling price of $3 €$ per unit, it is necessary that at least $50 \%$ of the olive wood is sold in order to get a positive profit. In the scenario of $50 \%$ and $100 \%$ of olive-wood used, economic values are respectively:

- for low productivity: from 4,000€ to $58,700 €$;

- for medium productivity: from $4,350 €$ to $63,400 €$;

- for high productivity: from $5,400 €$ to $78,600 €$. 


\subsection{Forage}

In the northern side of the park there is a local producer of cheese, who breeds 1200 sheep freely grazing every day. The quality of fresh available forage has a strong influence on both the wellness of animals and the quality of cheese [15]. Thus, this ES is an important factor in the production function of the local producer. Without this ES, he would be forced to buy other forage on local markets, spending money and losing specific organoleptic characteristics provided by the local plants.

Considering the average daily forage need of one sheep, we determine the annual forage intake, which is 35,850 tons of fresh grass. Given the local purchase price of an equal amount of similar grass, the avoided cost for the producer is $8,066 €$ per year.

\subsection{Water supply}

The last ES evaluated is the drinking water provided by the water supplier in Apulia to the 481 dwellings inside the park. The water consumed in 2008 (the only available data) was ca. $3,780,000 \mathrm{~m}^{3}$. Considering the regional fee for drinking water, that ranges between $0.59 € / \mathrm{m}^{3}$ and $2.34 € / \mathrm{m}^{3}$ depending on the quantity consumed [22], it implies ca. $91,350 €$ paid by users. This amount can represent a proxy for the ES of drinkable water provision. Though it results in a huge underestimation of the intrinsic value of water, it is a first valuable attempt to include this ES in the economic evaluation assessment [16].

In general, it is possible to use different economic methods to estimate the value of water, which can change according to several factors, such as quantity and quality consumed, usage, accessibility to the resource, and so on, but several physical and economic data are needed [16].

\section{Discussion and conclusion}

At a first level approximation, the sum of the five ES values, depicted in the previous section, is up to $0.3 \%$ of the total GDP of the 12 municipalities inside the park. It must be noticed that this proportion is not comprehensive of the overall ESs value provided by the park.

Our economic analysis provides only a small portion of all economic advantages obtained, or obtainable, from the ESs provided by the park. Furthermore, economic estimates are mainly based on market prices and therefore represent the lower bound of actual economic benefits. In fact, as shown in Table 1, more comprehensive economic methods can be used to evaluate benefits from ESs. Clean air, soil fertility, or conservation of genetic diversity are essential services provided by the park, and are not yet expressed in economic terms. Other important ESs, not evaluated here, like tourist activities and cultural values, could be assessed with Stated or Revealed Preferences methods, or Benefit Transfer. These methods require the collection of a large amount of data, not available at the time of this study. 
The economic evaluation provided in this study is only an example of the benefits produced by ESs in the park which may be valuable elements for an effective local and urban planning. However, the aim of the economic assessment of ESs is to give a clear and understandable message to decision makers and people, about the value that the ecosystems provide to societal well-being and economic development. In fact, the inventory of ESs and their evaluation can be strategically used for local planning. Moreover, decision-makers can also benefit from several mapping techniques, which can show local key-driver resources. A Geographical Information System (GIS) representation, for example, can provide a clear picture of an area and all the information related to the ESs spatial and temporal distribution. This can be of help to highlight the importance of a regional park and the ESs it provides for the development of a "local urban system", which includes people, economic activities and natural resources. The natural reserves play a key role in providing ESs and preserving the stock of natural resources. Any urban system depends on these services, and therefore ESs schould be taken into account in the decision-making processes. The ES's approach seems to be very useful in investigating the correlation between humans and nature and its use has grown rapidly in the last 20 years [21].

The ES's approach gives a complete overview on the different components natural, social, cultural and economic - of an area (e.g. a regional park). It encompasses the overall heritage located in a given geographical area and could be a very useful policy instrument for decision makers. Future development of ES inventorying and evaluation techniques, in connection with the evolution of human activities, will offer a better and deeper understanding of potential and limits in an area. This information should drive the policies towards investments on the main strategic assets - like, for example, biodiversity and ecosystem's resilience - and their sustainable management, in order to achieve the maximum benefits, in the long term, for the whole society.

The economic assessment of the ESs of the park analysed shows that several economic and environmental benefits are available in the area and a wise-informed development of the urban system can provide monetary incentive to local people, environmental maintenance of precious plants and animals and long term benefits for both human beings and natural systems.

\section{References}

[1] Prigogine I., From being to becoming. Time and complexity in the Physical Sciences. Freeman, San Francisco, 1980.

[2] Prigogine I. \& Stengers I., La nouvelle alliance. Métamorphose de la science. Gallimard, Paris, 1979.

[3] MA, Millennium Ecosystem Assessment. Ecosystem and Human WellBeing: Synthesis. Island press, Washington, DC, 2005.

[4] Council Directive 92/43/EEC of 21 May 1992 on the conservation of natural habitats and wild fauna and flora. 
[5] De Groot R.S., Wilson M.A., Boumans R.M.J., A typology for the classification, description and valuation of ecosystem functions, goods and services. Ecological Economics, 41, pp. 393-408, 2002.

[6] Fisher B., Turner K.T., Morling P., Defining and classifying ecosystem services for decision making. Ecological Economics, 68, pp. 643-653, 2009.

[7] Balmford A., Fisher B., Green R.E., Naidoo R., Strassburg B., Turner R.K., Rodrigues, A.S.L., Bringing Ecosystem Services into the Real World: an Operational Framework for Assessing the Economic Consequences of Losing Wild Nature. Environmental and Resource Economic, 48, pp. 161-175, 2011.

[8] UK NEA, National Ecosystem Assessment, The UK National Ecosystem Assessment: Synthesis of Key Findings. UNEP-WCMC, Cambridge, 2011.

[9] Bateman I.J., Mace G.M., Fezzi C., Atkinson G., Turner K., Economic Analysis for Ecosystem Service Assessments. Environmental and Resource Economic, 48, pp. 177-218, 2011.

[10] Ente Parco, Atlante del Parco. Piano Territoriale del Parco "Costa OtrantoS.M. di Leuca e Bosco di Tricase", 2013.

[11] IPCC, 2006 IPCC Guidelines for National Greenhouse Gas Inventories. Methodology report prepared by the National Greenhouse Gas Inventories Programme (Eggleston H.S., Buendia L., Miwa K., Ngara T., Tanabe K., eds.), IGES, Japan, 2006.

[12] DECC, Department of Energy \& Climate Change, UK Government, A brief guide to the carbon valuation methodology for UK policy appraisal. DECC, London, 2011.

[13] Tol R.S.J., The Economic Effects of Climate Change. Journal of Economic Perspective, 23, pp. 29-51, 2009.

[14] DECC, Department of Energy and Climate Change, Carbon Valuation in UK Policy Appraisal: A Revised Approach. DECC, London, 2009.

[15] Molle G., Decandia M., Buone pratiche di pascolamento delle greggi di pecore e capre (Associazione Regionale Allevatori della Sardegna ed.), Tip. Mulas, Cagliari, Italia, 2012.

[16] Morris J. \& Camino M., Economic Assessment of Freshwater, Wetland and Floodplain (FWF) Ecosystem Services. In: The UK Ecosystem Assessment Technical Report. UK National Ecosystem Assessment, UNEP-WMCM, Cambridge, 2011.

[17] Bateman I.J., Day B.H., Georgiou S., Lake I., The aggregation of environmental benefit values: Welfare measures, distance decay and total WTP. Ecological Economics, 60, pp. 450-460, 2006.

[18] Burkhard B., Kroll F., Nedkov S., Müller F., Mapping ecosystem service supply, demand and budgets. Ecological Indicators, 21, pp. 17-29, 2012.

[19] Nelson E., Mendoza G., Regetz J., Polasky S., Tallis H., Cameron D.R., Chan K., Daily G.C., Kareiva P.M., Lonsdorf E., Naidoo R., Ricketts T., Shaw R., Modeling multiple ecosystem services, biodiversity conservation, commodity production, and tradeoffs at landscape scales. Frontiers in Ecology and Environment, 7, pp. 4-11, 2009. 
[20] Sandhu H. S., Wratten S.D., Cullen R., Case B., The future of farming: the value of ecosystem services in conventional and organic arable land. An experimental approach. Ecological Economics, 64, pp. 835-848, 2008.

[21] Turner K.R., Paavola J., Cooper P., Farber S., Jessamy V., Georgiou S., Valuing nature: lessons learned and future research directions. Ecological Economics, 46, pp. 493-510, 2003.

[22] Bollettino Ufficiale della Regione Puglia - no. 77, 06-06-2013. 